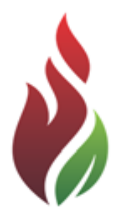

SUSTENERE

Publishing Corporation

\section{A PERCEPÇÃO DE OPORTUNIDADES NO CONTEXTO DO EMPREENDEDORISMO SOCIAL}

\section{RESUMO}

A literatura aponta a existência de dois tipos de empreendedorismo: o empreendedorismo comercial e o empreendedorismo social, cuja meta principal é alterar a realidade social seja pela existência de uma missão ou pela percepção de barreiras de entrada para o acesso a determinados mercados sociais. Nos estudos sobre o empreendedorismo comercial, a oportunidade é visualizada como uma possibilidade de se atender com sucesso necessidades insatisfeitas suficientemente grandes, o que resulta em lucro para o empreendedor. Já para o empreendedorismo social, a percepção de oportunidades não é de fácil compreensão, pois foge do tradicional sistema de exploração de oportunidades que tem por objetivo final a mera obtenção de lucros. Ao considerar o impacto das atividades de natureza social e as crescentes transformações que esse tipo de atividade sofreu nos últimos anos, sugere-se que essas aproximam-se do empreendedorismo. Partindo desse pressuposto, o objetivo desse estudo é compreender como as oportunidades são percebidas e exploradas na conjuntura do empreendedorismo social, visando responder a seguinte pergunta: de que forma essas oportunidades são percebidas dentro do contexto do empreendedorismo social? Para dar conta dessa temática, além do levantamento bibliográfico empreendido para o referencial teórico, um estudo de caso foi conduzido junto a um empreendimento social previamente escolhido por suas características, que se encaixava nos moldes estabelecidos pela bibliografia consultada. Foram realizadas entrevistas com o empreendedor social e alguns dos beneficiários dessa prática.

PALAVRAS-CHAVES: Oportunidade; Empreendedorismo Social; Estudo de Caso.

\section{PERCEPTION OF OPPORTUNITIES IN THE CONTEXT OF SOCIAL ENTREPRENEURSHIP}

\section{ABSTRACT}

The literature suggests the existence of two types of entrepreneurship: the commercial entrepreneurship and social entrepreneurship, whose main goal is to change the social reality to the existence of a task or the perception of barriers of entry for access to certain social markets. In studies on commercia entrepreneurship, opportunity is viewed as an opportunity to successfully meet sufficiently large unmet needs, which results in profit for the entrepreneur. As for social entrepreneurship, perception of opportunities is not easy to understand because it escapes the traditional system of exploitation of opportunities whose ultimate goal mere profit. When considering the impact of the activities of a socia nature and the increasing transformations that this type of activity has suffered in recent years, it is suggested that these approximate entrepreneurship. Based on this assumption, the goal of this study is to understand how opportunities are perceived and exploited in the context of social entrepreneurship, aiming to answer the following question: how these opportunities are perceived within the context of social entrepreneurship? To cope with this issue, in addition to bibliographic undertaken to the theoretical framework, a case study was conducted among a venture previously chosen for its characteristics, which fit in the manner established by the bibliography. Interviews with social entrepreneurs and some of the beneficiaries of this practice were made. We used the method of content analysis to examine the interviewees' statements.

KEYWORDS: Opportunity, Social Entrepreneurship, Case Study.
Revista Brasileira de

Administração Científica,

Aquidabã, v.5, n.3, Jul, Ago, Set,

Out, Nov, Dez 2014.

ISSN 2179-684X

SECTION: Articles

TOPIC: Empreendedorismo e Inovação

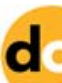

DOI: 10.6008/SPC2179-684X.2014.003.0014

Antônia Laís Costa Araújo Leal

Universidade Estadual do Ceará, Brasil http://lattes.cnpq.br/4488582645300773 laiscostaa@gmail.com

Ana Augusta Ferreira de Freitas Universidade Estadual do Ceará, Brasil http://lattes.cnpq.br/7023392308720934 freitas8@terra.com.br

\section{Emmanuelle Soraya}

Coelho dos Santos

Universidade Estadual do Ceará, Brasil http://lattes.cnpq.br/2012654218191204 sorayacs1@gmail.com

Received: 22/05/2014

Approved: 02/09/2014

Reviewed anonymously in the process of blind peer.

\section{Referencing this:}

LEAL, A. L. C. A.; FREITAS, A. A. F.; SANTOS, E. S. C. A percepção de oportunidades no contexto do empreendedorismo social. Revista Brasileira de Administração Científica, Aquidabã, v.5, n.3, p.236251, 2014. DOI: $h$ ttp://dx.doi.org/10.6008/SPC2179$684 X .2014 .003 .0014$ 


\section{INTRODUÇÃO}

Os problemas sociais são caracterizados pela insuficiência de ações eficazes do Estado e, por conta disso, a população é forçada a conviver com a falta de assistência à saúde, educação de baixa qualidade, falta de segurança e de saneamento básico, dentre outros. Estes são fatos amplamente divulgados pela mídia e se tornaram objetos de pesquisa de cientistas sociais e outros profissionais de áreas correlatas, preocupados com os diversos problemas sociais no país (ABREU \& ANDRÉ, 2006; TEIXEIRA \& PORTO, 1998; KAGEYAMA \& HOFFMANN, 2006). Estas mazelas e suas possíveis soluções requerem empreendimentos do Estado, os quais - muitas vezes - não chegam a ocorrer.

A desesperança da população com relação aos problemas da sociedade torna alguns indivíduos descrentes e acomodados (MINAYO, 1996). No entanto, para outros indivíduos, os mesmos problemas, em lugar de causar desânimo, conduzem ao desafio, levando-os a iniciar uma mobilização da sua força e do seu poder criador para induzir outros indivíduos a procurar por alternativas que solucionem os problemas do ambiente no qual vivem. Esse fenômeno atualmente é conhecido por empreendedorismo social, visto como uma nova forma de percepção empreendedora cujo objetivo principal é o de atender anseios - normalmente de natureza básica - não satisfeitos por seus responsáveis primários, representados em geral pelas figuras do Estado e do Governo (OLIVEIRA, 2004).

A literatura aponta a existência de dois tipos de empreendedorismo: o empreendedorismo comercial, voltado para a geração de resultados financeiros por meio da exploração de oportunidades visualizadas em necessidades não atendidas, gerindo-se adequadamente os recursos - humanos e econômicos - disponíveis para tanto (TIMMONS, 1994) e o empreendedorismo social, cuja meta principal é alterar a realidade social seja pela existência de uma missão ou pela percepção de barreiras de entrada para o acesso a determinados mercados sociais (CORNER \& HO, 2010).

Nos estudos sobre o empreendedorismo comercial, a oportunidade é visualizada como uma possibilidade de se atender com sucesso necessidades insatisfeitas suficientemente grandes, o que resulta em lucro para o empreendedor (HISRICH et al., 2009). No entanto, no empreendedorismo social, a percepção de oportunidades não é de fácil compreensão, pois foge do tradicional sistema de exploração de oportunidades que tem por objetivo final a mera obtenção de lucros. Mesmo sendo capaz de gerar resultados financeiros, o empreendedorismo social ligase conceptualmente à missão social geradora de mudanças.

No intuito de discutir estas questões, este trabalho tem como objeto de pesquisa a percepção da oportunidade dentro do empreendedorismo social, pois se entende que esta é o fulcro de qualquer ação empreendedora. A respeito deste assunto, alguns estudiosos (MAIR \& MARTI, 2006; MAIR \& NOBOA, 2006) discutem a concepção das oportunidades no contexto do empreendedorismo social, questionando-se se estas são encontradas ou criadas. A importância 
de pesquisar este tema é reforçada por dois estudos que fornecem evidências empíricas e corroboram que o reconhecimento da oportunidade é um tema chave no empreendedorismo social (SHAW \& CARTER, 2007; WEERAWARDENA \& MORT, 2006).

Partindo desse pressuposto, o objetivo desse estudo é compreender como as oportunidades são percebidas e exploradas na conjuntura do empreendedorismo social, visando responder a seguinte pergunta: de que forma essas oportunidades são percebidas dentro desse contexto? Para dar conta dessa temática, além do levantamento bibliográfico empreendido para o referencial teórico, um estudo de caso foi conduzido junto a um empreendimento social previamente escolhido por suas características, que se encaixava nos moldes estabelecidos pela bibliografia consultada.

\section{REVISÃO TEÓRICA}

Apesar de o empreendedorismo ser um campo de estudo antigo - foi definido pela primeira vez mais de 250 anos atrás (AUSTIN et al., 2006) -, atualmente sua importância tem sido destacada no intuito de promover e sustentar o progresso social e o desenvolvimento econômico. Dessa forma, surgiu o empreendedorismo social, um conceito ainda em construção, muito embora exista certo consenso entre os estudiosos quanto às semelhanças desse tipo de empreendedor com o empreendedor comercial (WEERAWARDENA \& MORT, 2006; SHAW \& CARTER, 2007). O que diferencia o empreendedorismo social do comercial é que o primeiro possui um forte apelo ao bem estar social em suas motivações.

Elkington e Hartigan (2008) consideram que não há uma definição sobre quem é o empreendedor social, mas reconhecem que há concordância sobre o que eles fazem: "é por meio da exploração de novas ideias que o empreendedor social cria empreendimentos que oferecem produtos e serviços comumente não apresentados no campo social”. Já Lowe e Marriot (2006) ressaltam a atuação dos empreendedores sociais, admitindo que além de operarem em um contexto econômico, eles também operam em um contexto social. Segundo esses autores "os empreendedores sociais tornam o sistema econômico mais competitivo, mas também desencadeiam mudanças na estrutura da sociedade - eles enriquecem a vida, desafiando o status quo, mudando percepções" (LOWE \& MARRIOT, 2006).

O empreendedor social é uma espécie no gênero empreendedor e o critério central para que assim seja classificado é que seu foco seja a missão social, e não a geração de riqueza, sendo esta última apenas um meio para o fim que deseja. Nas metas do empreendimento não há lugar para benefício do empreendedor (DESS, 1998).

Peredo (2005) aponta que há ampla concordância entre os estudiosos de que os empreendedores sociais e seus empreendimentos são guiados por metas sociais, que é o desejo de beneficiar a sociedade de alguma forma, visto pela autora como outra maneira de asseverar que este empreendedor pretende aumentar o valor social. Entretanto, ela admite a existência de 
uma discussão a respeito da relação entre metas sociais e o status de organização sem fins de lucro que gera o seguinte questionamento: o empreendedor social pode ou não obter algum tipo de renda ou remuneração a partir da receita das atividades de um empreendimento social? O The Northland Institute, entidade fundada em 1996 para aperfeiçoar a efetividade de organizações de desenvolvimento comunitário, defende o modelo que cita a arte de simultaneamente perseguir objetivos financeiros e sociais. Já Peredo (2005) afirma que os empreendimentos sociais devem ser batizados de híbridos, pois combinam características de organizações com fins lucrativos e sem fins lucrativos.

Dess et al. (2003) consideram o empreendedorismo social no mundo das organizações sem fins lucrativos - essa ideia pode incluir as organizações focadas em disponibilizar mercadorias e serviços sem se comprometer em distribuir renda para os seus integrantes. Para esses autores, o empreendedorismo social sugere encontrar novos modos de criar e sustentar valor social. É possível encontrar empreendedores sociais criando formas de disponibilizar abrigo, saúde ou educação para as pessoas sem necessariamente cobrar taxas ou visar retorno por parte de seus beneficiários.

A definição de empreendedor social adotada nesse trabalho tem como base os elementos reconhecidos por Dess (1998): empreendedor social é uma espécie do gênero empreendedor que tem como foco a missão social e que age por meio do reconhecimento e da busca de oportunidades, em um processo de contínua inovação, adaptação e aprendizado para que se chegue ao cumprimento dessa missão.

As oportunidades são fontes para ideias de negócios (BATEMAN \& SNELL; 1996). Assim, são fontes de ideias e oportunidades: descobertas tecnológicas, acontecimentos econômicos, mudanças demográficas e de estilos de vida, calamidades e desastres naturais, mudanças governamentais e descobertas de recursos. A oportunidade, portanto, é um conjunto favorável de circunstâncias para fazer algo, como a criação de um novo empreendimento.

Estudiosos defendem que o reconhecimento de oportunidades é o foco de análise do fenômeno do empreendedorismo (ECKHARDT \& SHANE, 2003; SHANE \& VENKATARAMAN, 2000; SINGH, 2001). Para Casson (1982), o reconhecimento e a exploração de oportunidades são o centro do empreendedorismo. Pode-se dizer, ainda, que a noção de oportunidade está no coração do empreendedorismo - seja ele social ou comercial (MAIR; MARTI, 2006). Autores como Robinson (2006), Austin et al. (2006), Dorado (2006) e Mair e Martí (2006) reconhecem que apesar da proximidade, as oportunidades do empreendedorismo social são diferentes das oportunidades do empreendedorismo comercial. Segundo esses autores, as oportunidades do empreendedorismo social estão focadas em problemas sociais, pois envolvem tentativas de criar valor social, buscando solucionar questões sociais, tais como geração de renda para os economicamente desfavorecidos. É por meio deste ativismo que as oportunidades aproveitadas criam valor social, tendo como expoentes ações de comércio justo e ações de autoajuda - sendo 
essas últimas consideradas ações de capacitação para as pessoas, semelhantes ao sistema de micro finanças (HOCKERTS, 2006).

Robinson (2006) aponta um segundo caminho para o reconhecimento de oportunidades no empreendedorismo social e descreve que elas estão inseridas em uma conjuntura social ou comunidade específica. Por isso, para esse autor, os empreendedores sociais podem encontrar barreiras sociais e institucionais para explorar tais oportunidades. Para tratar das oportunidades na situação sugerida por Robinson (2006), surgiram formas organizacionais únicas - empresas sociais que tomam a forma de organizações híbridas, tendo fins lucrativos, mas, por serem orientadas pela sua missão, assumem características de empresas sem fins lucrativos (HOCKERTS, 2006; MORT et al., 2003; PEREDO, 2005).

Shaw e Carter (2007) sugerem que as oportunidades no empreendedorismo social são percebidas coletivamente e que só é possível explorá-las dessa forma. É a teoria da ação coletiva: à primeira vista, pode parecer que essa teoria se resuma na evidência empírica apontada por empreendedores sociais, os quais que reconhecem a participação de outras pessoas, de outras organizações e de voluntários em seus empreendimentos. No entanto, uma consideração mais profunda dos padrões de ação coletiva sugere os motivos pelos quais os atores se aglutinam para criar valor social - eles se unem porque o conhecimento necessário em cada episódio de inovação não é possuído por uma única pessoa, mas está disperso em múltiplos atores.

Já Weerawardena e Mort (2006) defendem que as oportunidades do empreendedorismo social são semelhantes às do empreendedorismo comercial, onde o reconhecimento de oportunidades de criar ou inovar é insight de um único indivíduo, tornando-se o ponto de início do processo empresarial. Por exemplo, o reconhecimento de oportunidade para um empreendedor social pode ser determinado por uma missão social ou por barreiras sociais e institucionais para a entrada em um mercado em particular. Além disso, os estudiosos especulam que o empreendedor social pode moldar as oportunidades que ele reconhece - essa ideia é consistente com os achados da literatura sobre empreendedorismo comercial, que mostrou que o empreendedor nessa situação - adapta as oportunidades que percebe.

\section{METODOLOGIA}

O presente estudo caracteriza-se como uma pesquisa qualitativa de natureza exploratória, pois explora o contexto das oportunidades em categorias pré-definidas. Opondo-se aos estudos quantitativos - embasados por hipóteses claramente estabelecidas, buscando evitar distorções a natureza qualitativa de uma pesquisa permite que, ao longo de seu desenvolvimento, as principais questões sejam definidas (GODOY, 1995). De maneira preliminar, foi feito um levantamento bibliográfico. Nessa etapa, conceitos e abordagens foram resgatados com o intuito de esclarecer e dar um norte à investigação. A pesquisa teórica conduziu à análise dos conceitos de empreendedorismo social (ELKINGTON \& HARTIGAN, 2008; LOWE \& MARRIOT, 2006) e 
oportunidade (BATEMAN \& SNELL, 1996), sendo ambos os assuntos discutidos anteriormente. Essa fase precedeu a pesquisa de campo, de forma a permitir o embasamento necessário no momento da observação.

Pela própria natureza desta investigação, foi escolhido o estudo de caso, aqui entendido como uma estratégia investigativa cujo objeto de análise seja contemporâneo e os limites entre esse fenômeno e o contexto em que se insere não sejam claros (YIN, 2001). Ao considerar os objetivos do presente estudo, ele será categorizado como instrumental - quando, a partir de um caso, analisa-se um fator mais amplo, servindo para orientar estudos e guiar novas pesquisas (VENTURA, 2007).

$\mathrm{Na}$ busca por um objeto contemporâneo para análise do fenômeno do empreendedorismo social, chegou-se a Steve West, um empreendedor social que possui uma organização denominada Cross Trade - que atua por meio de um portal na internet, tendo por tema o empreendedorismo social. Nesse site ele escreve artigos e vende produtos oriundos de sua atividade social. Foi visitando este sítio eletrônico que chegou-se às louceiras da Família Pequeno, residentes em Córrego de Areia, no Estado do Ceará, apontadas entre os beneficiados pelas atividades do empreendedor.

Uma vez definido o objeto de pesquisa, iniciou-se um trabalho baseado na pesquisa bibliográfica realizada, transformando em questionamentos os pontos considerados como os mais relevantes, até chegar às formas definitivas que seriam aplicadas - em forma de entrevista - aos atores envolvidos nessa cadeia de relacionamentos desenvolvida pelo empreendimento. Inicialmente estes seriam apenas as louceiras e o empreendedor social. Contudo, ao ser realizada a primeira entrevista, constatou-se a existência de um terceiro ator, uma espécie de intermediário entre Steve West e as beneficiadas de Córrego de Areia.

A entrevista inicial foi realizada com as louceiras da Família Pequeno, no mês de setembro de 2012, buscando inferir como estava estabelecida a relação entre elas e o empreendedor e de que forma isso impactava na maneira como conduziam seu negócio e em suas vidas. A partir dessa entrevista, chegou-se a um intermediário da relação, que após ser contatado, forneceu as informações inicias a respeito do empreendimento de Steve West, bem como seu endereço eletrônico. Foi por meio do intermediário que chegou a Steve West - entrevistado nos meses de outubro e novembro de 2012 - que reside nos Estados Unidos e que se prontificou a responder a entrevista, realizada por meio de documento no Google Docs, uma ferramenta de armazenamento e compartilhamento de documentos nas nuvens. Todas as entrevistas realizadas foram baseadas no levantamento bibliográfico preliminar, visando manter a linha de pesquisa adotada. Portanto, trata-se de um estudo de corte transversal, pois foi realizado em dado momento do tempo.

Nesse estudo são usadas categorias como referencial de análise. Para um melhor entendimento, conceitua-se categoria como sendo um conjunto que abrange elementos ou aspectos com características comuns ou que se relacionam entre si (MINAYO, 1996). Assim, transformou-se a informação obtida junto aos entrevistados em algo interpretável, que teve 
significado para as autoras. Berelson (1952), a propósito da escolha das categorias, afirma que "os estudos serão produtivos na medida em que as categorias sejam claramente formuladas e bem adaptadas ao problema e ao conteúdo a analisar". As categorias gerais e específicas identificadas compõem os conjuntos expostos na Figura 1. Utilizou-se o software Atlas TI versão 6.0 para organizar as categorias de análise.

Quadro: Categorias de análise

\begin{tabular}{|c|c|c|}
\hline Categorias de Análise & Descrição & Referências \\
\hline $\begin{array}{l}\text { Característic as das } \\
\text { Oportunidades }\end{array}$ & $\begin{array}{l}\text { - São percebidas coletivamente; } \\
\text { - Oriundas de insights de um só } \\
\text { indivíduo. }\end{array}$ & $\begin{array}{c}\text { - Shaw \& Carter (2007); } \\
\text { - Weerawardena \& Mort (2006) }\end{array}$ \\
\hline $\begin{array}{l}\text { Características do } \\
\text { Empreendedor }\end{array}$ & $\begin{array}{l}\text { - Foco na obtenção de lucro; } \\
\text { - Foco na missão social; } \\
\text { - Foco nos problemas sociais; } \\
\text { - Foco na transformação social; } \\
\text { - Tornam o ambiente econômico } \\
\text { mais competitivo, porém } \\
\text { também desencadeiam } \\
\text { mudanças na sociedade }\end{array}$ & $\begin{array}{l}\text { - Hisrich; Peters, She pherd } \\
\qquad(2009) ; \\
\text { - Dess (1998); } \\
\text { - Robin son (2006); Austin et al. } \\
\text { (2006); Dorado (2006); Mair \& } \\
\text { Martí (2006); } \\
\text { - Lowe \& Marriot (2006) }\end{array}$ \\
\hline $\begin{array}{l}\text { Características do } \\
\text { Empreend imento }\end{array}$ & $\begin{array}{l}\text { - Operam em um contexto } \\
\text { econômico e social; } \\
\text { - O o bjetivo primário não é o de } \\
\text { beneficiar o empreendedor; } \\
\text { - Contínua inovação e } \\
\text { ada ptação; } \\
\\
\text { - Aprendizado constante para } \\
\text { manter a missão social. }\end{array}$ & - Lowe \& Marriot (2006); \\
\hline Contexto de Criação & $\begin{array}{l}\text { - Contexto de necessidades } \\
\text { sociais percebidas; } \\
\text { - Existência de barreiras de } \\
\text { entrada para o mercado social }\end{array}$ & $\begin{array}{c}\text { - Robinson (2006); Austin et al. } \\
\text { (2006); Dorado (2006); Mair \& } \\
\text { Marti (2006); } \\
\text { - Corner \& Ho (2010) }\end{array}$ \\
\hline
\end{tabular}

Concluída essa etapa, foi utilizada a análise de conteúdo, definida por Bardin (2011) como o 'conjunto de técnicas de análise das comunicações, que utiliza procedimentos sistemáticos e objetivos de descrição do conteúdo das mensagens para a análise dos dados'. Esse conjunto de técnicas abre espaço para que sejam feitas inferências lógicas quanto à problemática estabelecida, gerando duas questões: (ii) O que levou a determinado enunciado?; (ii) Quais são 
as suas prováveis consequências? (BARDIN, 2006). Vista por essa ótica, a análise de dados é uma metodologia que aprimora a leitura destes e permite a ultrapassagem de determinadas incertezas (MOZZATO \& GRZYBOVSKI, 2011).

A análise de conteúdo pode ser elencada em três fases, conforme determinado por Bardin (2006). Essas etapas estão sequenciadas da seguinte maneira: a) pré análise, que corresponde ao momento de organização do material mais relevante para a pesquisa; b) exploração do material, onde os dados brutos separados anteriormente são analisados de forma a criar categorias de análise e unidades de registro e que no presente trabalho corresponde à elaboração da Figura 1, que descreve as categorias de análise escolhidas; c) tratamento dos resultados etapa em que há a interpretação das inferências construídas e análise dos resultados.

\section{RESULTADOS E DISCUSSÃO}

Steve West teve o seu interesse pelo Brasil despertado no ano de 1993, quando ouviu um programa de rádio lamentando a situação das crianças nesse país e começou a procurar informações sobre a adoção de crianças brasileiras. Ele era proprietário de uma empresa de seguros e já tinha quatro filhos naturais quando adotou quatro crianças brasileiras. Antes da realização de cada adoção, West foi obrigado a conviver com as crianças em seus orfanatos, na cidade de São Paulo, por 30 dias. Nesse período, ele adquiriu hábitos brasileiros, aprendendo, inclusive, a falar português.

Há dezoito anos, West conheceu Auzelio Santini, que é brasileiro, na Flórida, e os dois começaram a fazer viagens para o Brasil, pois West estava expandindo seu negócio de seguros para a América do Sul. Segundo West, "nós trabalhávamos a semana toda e íamos visitar feiras de artesanato local nos fins de semana. No início, era apenas um hobby, mas logo se tornou uma missão, e a ideia da Cross Trade nasceu".

A Cross Trade iniciou suas operações em 2003, desenvolvendo relacionamentos com oito famílias localizadas no Ceará. Desde então, mais de cinquenta famílias, em seis Estados brasileiros - Amazonas, Pará, Maranhão, Piauí, Ceará, Minas Gerais e Tocantins - fazem parte do negócio. Elas atuam em áreas não-turísticas, distantes da atividade econômica de seus Estados. Em 2008, um depósito foi construído no Maranhão, designado como o Estado mais pobre do Brasil. Esse depósito funciona como um ponto de apoio logístico para as operações da Cross Trade, e é fundamental para as demais localidades beneficiadas, pois ajuda a controlar o transporte nacional e as despesas com armazenamento. Em 2012, a Cross Trade começou a apoiar uma oficina de madeira para os homens e mulheres desempregados na cidade de Barra do Corda, no Maranhão.

$\mathrm{Na}$ entrevista realizada com as louceiras da família Pequeno, fica claro que Steve West é praticamente o único destinatário das peças fabricadas, como afirma Maria Pequeno na seguinte frase: "O trabalho que eu faço aqui é o pessoal dos Estados Unidos que compra." Embora 
algumas peças sejam vendidas para a Ceart e - quando há disponibilidade - para pessoas que por ventura visitem a residência das louceiras, quase toda a produção é escoada para a Cross Trade. No entanto, não há impacto negativo nisso na visão de Maria Pequeno: "Foi melhor, porque eu não tenho transporte para levar para vender na rua. Porque se eu levar para a rua, eu vendo tudo. Mas eu não tenho transporte, não posso pagar um transporte para levar pra vender. E quando sobra algo, tenho que pagar outro transporte para trazer de volta para casa. Como o americano vem comprar na minha casa, eu acho melhor, pois eles levam tudo."

O trabalho social de West não se resume a esse ponto. As louceiras declaram ainda que seus produtos são comprados por um valor acima do usualmente cobrado, embora, ao serem questionadas, elas não saibam explicar o motivo:

“Eu vendo aqui a $\mathrm{R} \$$ 80,00 (ao ser questionada sobre o valor dos kits de louça para feijoada). Mas o pastor compra mais caro, ele compra por $\mathrm{R} \$ 100,00$. (...) Todas as louças são compradas por ele por um valor mais alto do que eu costumo vender. Esta peça aqui, por exemplo, é vendida a dez reais e ele compra por doze reais. Uma vez ele disse que o pessoal da transportadora não teve cuidado com as peças, o que causou prejuízo. Se não fosse isso, o valor das peças iria ser aumentado. Eles são muito bons para fazer negócio."

Segundo Steve West, o objetivo da Cross Trade é modificar ou mudar completamente os produtos criados pelas famílias brasileiras, a fim de melhorar as vendas e aumentar a possibilidade de comercialização. Para isso, são feitas duas visitas por ano a cada família, com o propósito de discutir alterações nos produtos e novas formas de aumentar a renda familiar com novos equipamentos e alternativas na aquisição de matéria-prima.

O início do relacionamento entre a Cross Trade e a família a ser assistida é feita da seguinte forma: empréstimos sem juros para a aquisição de equipamentos são disponibilizados para cada grupo familiar, conforme necessário. O reembolso não começa até que o produto comece a vender. Então a família tem três anos para pagar o empréstimo. Esse relacionamento entre o empreendedor social e as famílias assistidas é o que diferencia as atividades de empreendedorismo social das atividades meramente assistencialistas ou filantrópicas: há sinais óbvios de efeitos benéficos para as famílias, tais como cozinhar com gás em vez de com lenha, aquisição de novos aparelhos eletrônicos, computadores para as crianças, ferramentas de trabalho melhores, dentre outros. Alguns destes benefícios podem ser atribuídos a compras de produtos pela Cross Trade. Mas, segundo West, deve-se ter cuidado para que a Cross Trade não tome o crédito único para estas mudanças, pois "as famílias brasileiras trabalham arduamente".

Steve West resume os préstimos de seu empreendimento da seguinte forma: "a sociedade é beneficiada de duas maneiras: as famílias brasileiras se tornam grandes consumidores de bens e serviços de saúde e educação, melhorando as condições para a próxima geração, e as despesas pagas pela Cross Trade como aluguel de galpão, transporte de produtos, propaganda e impostos sobre vendas, proporcionam renda para outros além dessas famílias. Ademais, os produtos vendidos proporcionam benefícios (prazeres) para aqueles que compram". E enfatiza 
que as oportunidades no contexto do empreendedorismo social visam impactar uma parte da sociedade, com lucro e retorno sobre o capital como um objetivo secundário. A definição mais estrita inclui uma "escala de impacto mensurável", que seria diretamente mudar para melhor uma grande porção da sociedade.

Para o desenvolvimento de suas atividades no Brasil, Steve West conta com o apoio de uma equipe fixada neste país, que trabalha junto aos beneficiados. Dois membros da equipe estão em contato constante com cada um deles. Assim que a renda começa a ser gerada por meio das compras feitas via Cross Trade, os beneficiados devem comprar um telefone celular pré-pago para manter contato com a equipe quanto às negociações. Como a maioria das famílias não possuía contas bancárias antes de conhecer a Cross Trade, cabe à equipe fornecer assistência na abertura de uma conta corrente em um banco próximo, tornando possível pagar cada família por meio de depósitos eletrônicos. Geralmente, vários beneficiados se unem e indicam uma única família para lidar com as transações bancárias - o que indica um nível de confiança rara atualmente.

O empreendedor afirma criar oportunidades na medida em que proporciona um mercado para os artigos produzidos pelas famílias, empréstimos sem juros com um período de pagamento viável e investimento em novos produtos, além de fornecer divulgação e marketing nos Estados Unidos. De acordo com West, as pessoas pobres são incapazes de se arriscar em novos produtos, e as falhas de novas tentativas podem ser caras e até mesmo afetar a segurança alimentar de suas famílias. Logo, é a Cross Trade que assume o risco dos novos produtos, pagando um salário por hora e fornecendo um mercado garantido durante o período de desenvolvimento do trabalho.

\section{A Oportunidade como Fulcro da Ação Empreendedora na Cross Trade}

Steve West, segundo suas próprias palavras, é "um homem que tem capacidade para enxergar oportunidades e fazê-las acontecer". A experiência no Brasil marcou West pela chance de "ajudar o próximo". A forma como avalia cada situação revela muito da sua experiência de vida: sua antiga profissão o ensinou a entender o setor público, o trabalhar para o coletivo. Tanta insistência em trabalhar com o social o fez tomar decisões que culminaram na criação da Cross Trade.

A fim de compreender a realidade na qual pretendia inserir seu empreendimento, West atuou como militante, seguiu cadeias de produção, conviveu com trabalhadores rurais e assimilou críticas. Nessa fase seu objetivo era perceber como tornar a distribuição de renda mais igualitária ao número máximo de pessoas. Aqui chega-se à primeira categoria de análise: o perfil diferencial. Steve West opera em um contexto econômico e social, pois, ao passo que auxilia as famílias a tornarem seus produtos mais competitivos, objetivando o aumento de suas rendas, desencadeia com esse esforço - mudanças na sociedade em que vivem essas pessoas, pois há um 
aquecimento da economia local. Além disso, ressalta-se que West apresenta foco na missão social, e não na obtenção de lucro.

No referencial teórico percebe-se que há duas vertentes para o conceito de oportunidades. A primeira, defendida principalmente por Shaw e Carter (2007) sugere que as oportunidades no empreendedorismo social são apreendidas de forma coletiva, enquanto a segunda diz respeito à semelhança que as oportunidades do empreendedorismo social têm com as do empreendedorismo comercial, nas quais o reconhecimento de oportunidades é insight de um único indivíduo (WEERAWARDENA \& MORT, 2006). A análise deste caso específico mostrou que o insight surgiu de um único individuo, pois foi Steve West quem enxergou na carência das famílias brasileiras a chance de criar um negócio social. Embora tenha contado com a ajuda de Santini para implementar sua ideia, foi West quem criou a organização. Além disso, a despeito de a Cross Trade gerar lucro - suficiente para manter a estrutura básica de suas atividades - o foco está nos problemas sociais.

A segunda categoria de análise diz respeito ao objetivo do empreendedor, que, segundo Dess (1998), relaciona-se com a contínua inovação e adaptação ao mercado. É o que acontece na Cross Trade: West está sempre em busca de novas famílias de forma a oferecer produtos diversificados a seus compradores. Além disso, os próprios participantes do projeto, como já afirmado, estão em constante inovação e recebem incentivo para isso, seja por meio de financiamento para a aquisição de novos equipamentos ou pela orientação dada por West e sua equipe para adaptação dos produtos de acordo com a demanda. Como estes são vendidos em um site, há consumidores de diversos países do mundo, principalmente americanos. De acordo com o empreendedor, "por diferenças culturais, o gosto dos consumidores é desigual. Cores e formas diferentes são exigidas, sob pena de não haver público comprador suficiente".

A terceira categoria sugerida, chamada de características do empreendimento, foca-se na transformação social e no benefício de terceiros com a criação do negócio. Percebeu-se - assim como especulam estudiosos - que o empreendedor social pode moldar as oportunidades reconhecidas por ele, o que condiz com a literatura sobre empreendedorismo comercial, a qual mostrou que o empreendedor adapta as oportunidades percebidas. West adaptou a oportunidade encontrada à sua realidade: criou uma organização no país onde vive, ainda que para auxiliar as famílias brasileiras, pois seu foco está na transformação social dos que considera mais necessitados. Além disso, os benefícios gerados pelo empreendimento são destinados às famílias assistidas, e não ao próprio criador do negócio. As ações de West vão ao encontro do que afirma Robinson (2006), pois as famílias assessoradas estão inseridas em comunidades específicas, como a de Córrego de Areia, por exemplo.

A quarta categoria de análise refere-se ao contexto de criação do empreendimento social. Essa categoria analisa o contexto de necessidades sociais percebidas e a existência de barreiras de entrada para o mercado. As necessidades percebidas são baseadas nas percepções, na maneira como alguém entende um problema, o julga e toma uma iniciativa - West entendeu a 
pobreza das famílias brasileiras como uma oportunidade de ajudá-las, e a ação que adotou foi criar um empreendimento capaz de promover a melhoria das condições de vida destas.

Ainda sobre a quinta categoria, segundo Robinson (2006), os empreendedores sociais podem encontrar barreiras sociais e institucionais para explorar as oportunidades. É o que acontece com West: a primeira barreira diz respeito à forma inconsistente de cobrança de ICMS de Estado para Estado. Como exemplo têm-se o Ceará, o qual cobra ICMS para produtos artesanais oriundos de outros Estados como Maranhão, Pará, Piauí e Tocantins (com os quais West trabalha), apesar de não cobrar ICMS para produtos feitos no Ceará e vendidos para exportação. Logo, West exporta via Espirito Santos e São Paulo, que não cobram o ICMS, arcando, contudo, com maiores custos de transporte doméstico para que os produtos cheguem até esses portos.

Outra barreira encontrada relaciona-se com a burocracia brasileira - exigência de elaboração de relatórios e outros requisitos legais para as cooperativas. No Maranhão, West criou uma cooperativa de treinamento para que os próprios artesãos tirassem suas notas fiscais. No entanto, depois de três anos, a cooperativa foi interrompida, devido aos altos custos dos relatórios exigidos pelo governo e à obrigatoriedade da contratação de um contador. Quanto ao último item, os relatórios do contador contratado eram inconsistentes, causando atrasos de até um mês para que os artesãos recebessem as transferências eletrônicas de dinheiro dos EUA, pela não liberação dos bancos.

Um último obstáculo diz respeito à morosidade de alguns artesãos, o que causa problemas nas datas de envio dos produtos para exportação. Por isso, West começou a dar mais atenção às famílias lentas, para incentivá-las a atender às datas de envio - o empreendedor social e sua equipe promovem um treinamento, uma espécie de simulação de exportação com deadline para entrega dos artesanatos e preenchimento de documentos, a fim de melhorar o desempenho dessas famílias.

\section{CONCLUSÕES}

As análises obtidas nesse trabalho contribuem para a compreensão do processo de percepção e exploração de oportunidades por um empreendedor social, bem como a concepção sobre o que é o empreendedorismo social e quais suas diferenças com o empreendedorismo comercial. Para tanto, por meio dessa pesquisa foram identificadas as oportunidades percebidas pelo empreendimento social Cross Trade e as características dessas oportunidades, bem como as características do empreendedor social e do empreendimento estudado, além de seu contexto de criação, conforme sugerem as categorias de análise aqui abordadas.

Os resultados dessa pesquisa sugerem que a oportunidade no contexto do empreendedorismo social dever ser entendida como foco de análise desse fenômeno, assim como acontece no empreendedorismo comercial. A percepção de oportunidades no 
empreendedorismo social pode ser entendida como seu principal e mais importante aspecto, pois, muito embora a apreensão de oportunidades dentro dessa realidade seja relativamente mais simples do que no empreendedorismo comercial, a maneira como o empreendedor trabalha com as ferramentas disponíveis, dentro dos limites estabelecidos pelas barreiras(de natureza social e institucional) é de enorme complexidade e é o que realmente diferencia o empreendedorismo social dos demais tipos de empreendedorismo.

É justamente a oportunidade que difere o empreendedorismo social do comercial: no primeiro, a percepção da oportunidade não visa o benefício do próprio empreendedor - ele até pode se beneficiar dela, mas o interesse maior é o benefício de terceiros. Já no empreendedorismo comercial a oportunidade percebida visa o benefício do empreendedor, principalmente. Em suma, as oportunidades no empreendedorismo social estão focadas em problemas sociais, tendo como objetivo solucionar questões sociais, problemas de outrem, e não os problemas de quem as percebeu - como por exemplo a geração de renda para os economicamente desfavorecidos. Assim, os empreendimentos sociais são uma resposta de empreendedores que percebem oportunidades de negócio associadas às necessidades de uma comunidade ou população.

Assim, foi possível notar que as oportunidades no âmbito do empreendedorismo social tendem a impactar uma parte da sociedade, sendo o lucro e o retorno sobre o capital um objetivo secundário de quem se propõe a realizar o negócio. Em sentido mais exato, o empreendedorismo social inclui uma escala de impacto mensurável, que seria diretamente mudar para melhor uma grande porção da sociedade.

Faz-se necessário discorrer sobre os resultados encontrados nesse trabalho em relação ao quadro teórico sugerido na metodologia. Assim, corrobora com as ideias de Weerawardena e Mort (2006) o resultado encontrado no presente estudo no que diz respeito as oportunidades, tendo em vista que estas, no âmbito do empreendimento social estudado, foram oriundas de um só indivíduo - Steve West, na medida em que este percebeu que podia ser criado um negócio para que fosse aumentada a renda de algumas comunidades brasileiras, a fim de melhorar a qualidade de vida destas. No entanto, quanto as características do empreendedor, o resultado encontrado vai contra o sugerido por Hisrich (2009) e Peters e Shepherd (2009), que afirmam que o foco dos indivíduos empreendedores está no lucro. Entendeu-se que o empreendedor em questão apresentou, ao contrário, foco na missão e nos problemas sociais e foco na transformação social. Além disso, Steve West tornou o ambiente econômico mais competitivo, porém também desencadeou mudanças na sociedade, o que vai de encontro ao que afirmam alguns estudiosos (DESS, 1998; ROBINSON, 2006; AUSTIN et al., 2006; DORADO, 2006; MAIR \& MARTÍ, 2006; LOWE \& MARRIOT, 2006).

Ainda com relação ao quadro teórico - categorias de análise - o estudo apurou que as características da Cross Trade vão de acordo com o sugerido por Lowe e Marriot (2006) e Dess (1998), pois o empreendimento opera em um contexto econômico e social determinado, ou seja, 
as famílias pobres do Nordeste brasileiro. Além disso, tem como objetivo primário o benefício de terceiros, opera em contínua inovação e adaptação, principalmente por conta de as vendas serem destinadas ao mercado externo e há aprendizado constante para que a missão social inicialmente proposta seja mantida - o que esse trabalho comprovou foi que o aprendizado surge por meio da relação entre as famílias beneficiadas e o empreendedor social, bem como entre o empreendedor e os consumidores, na medida em que estes fazem exigências e aquele deve adaptar os produtos para venda. Quanto ao contexto de criação do empreendimento, percebeu-se que foi criado no contexto de necessidades sociais percebidas, conforme defendem Robinson (2006); Austin et al. (2006); Dorado (2006) e Mair e Martí (2006). Também foi possível encontrar, por meio de depoimento do empreendedor, a existência de barreiras de entrada para o mercado social, tais como a forma inconsistente de cobrança de ICMS de Estado para Estado e ainda a morosidade de alguns artesãos.

Acredita-se que este trabalho cumpriu seu objetivo, que era verificar qual a acepção de oportunidade na conjuntura do empreendedorismo social. Utilizou-se a Cross Trade como objeto de estudo e foi possível perceber as circunstâncias que levam à criação desse tipo de oportunidades. Ainda foi feita uma relação entre o empreendedorismo social e o empreendedorismo comercial. Vale ressaltar as limitações da pesquisa o acesso aos dados sobre empreendedorismo social são relativamente restritos, por se tratar de uma nova abordagem para um conceito recente. Mesmo na própria Cross Trade, a concessão de algumas informações foi dificultosa, mas o que não impediu uma boa análise dos dados que se tinha em disponibilidade. No entanto, é importe ressaltar que o trabalho se trata de um estudo de caso, não podendo os dados serem generalizados.

Como sugestão para estudos futuros, a diferença entre os dois tipos de empreendedorismo poderia ser melhor avaliada, bem como a influência do histórico de vida profissional e pessoal do empreendedor social no processo de criação de um negócio social. Além disso, é importante avaliar o empreendedorismo social para além da criação da oportunidade, sugere-se, então, aferir se as condições sociais dos trabalhadores envolvidos no negócio realmente estão melhores e a opinião desses atores sobre o empreendedorismo social.

\section{REFERÊNCIAS}

ABREU, A.; ANDRÉ, I.. Dimensões e espaços da inovação social. Revista Portuguesa de Geografia, Lisboa, v.41, n.81, p.121-141, 2006.

AUSTIN, J.; STEVENSON, H.; WEI-SKILLERN, J.. Social and commercial entrepreneurship: same, different, or both? Entrepreneurship Theory and Practice, Texas, v.30, n.1, p.1-22, 2006.

BATEMAN, T. S.; SNELL, S. A.. Management: building competitive advantage. 2 ed. Burr Ridge, IL: Richard D. Irwin, Inc., 1996.

BERELSON, B.. Content analysis in communication research. 1 ed. Glencoe: Free Press, 1952. 
CASSON, M. C.. The entrepreneur and economic theory. 3 ed. New Jersey: Barnes \& Noble Books, 1982.

CORNER, P. D.; HO, M.. How Opportunities Develop in Social Entrepreneurship. Entrepreneurship Theory and Practice. Texas, v.34, n.4, p.635-659, 2010.

DESS J. G.; IRELAND R. D.; ZAHRA S. A.; FLOYD S. W.; JANNEY J. J.; LANE P. J.. Emerging Issues in Corporate Entrepreneurship. Journal of Management, Nova lorque, v.29, n.3, p.351-378, 2003.

DESS, J. G.. The meaning of 'social entrepreneurship': Draft report for the kauffmann center for entrepreneurial leadership. 1 ed. California: Standford University, 1998.

DORADO, S.. Social entrepreneurial ventures: Different values so different process of creation, no?. Journal of Developmental Entrepreneurship, Singapura, v.11, n.4, p.319-343, 2006.

ECKHARDT, J.; SHANE, S.. Opportunities and entrepreneurship. Journal of Management, Nova lorque, v.29, n.3, p.333-349, 2003.

ELKINGTON, J.; HARTIGAN, P.. The power of unreasonable people: how social entrepreneurs create markets that change the world. 2 ed. Boston, MA: Harvard Business Press, 2008.

GODOY, A. S.. Introdução a pesquisa qualitativa e suas possibilidades. Revista de Administração de Empresas, São Paulo, v.35, n.2, p.57-63, 1995.

HISRICH, R. D.; PETERS, M. P.; SHEPHERD, D. A.. Empreendedorismo. 7 ed. Porto Alegre: Bookman, 2009.

HOCKERTS, K.. Entrepreneurial opportunity in social purpose business ventures. In: MAIR, J.. Social entrepreneurship. New York: Macmillan, p.142-154, 2006.

KAGEYAMA, A.; HOFFMANN, R.. Pobreza no Brasil: uma perspectiva multidimensional. Economia e Sociedade, São Paulo, v.15, n.1, p.79-112, 2006.

LOWE, R.; MARRIOT, S.. Enterprise: entrepeneurship and inovation. Concepts, contexts and commercialization. 1 ed. Elsevier: Butterworth-Heinemann, 2006.

MAIR, J.; MARTÍ, I. Social entrepreneurship research: a source of explanation, prediction, and delight. Journal of World Business, v.41, n.1, p.36-44. 2006.

MAIR, J.; NOBOA, E.. Social entrepreneurship: How intentions to create a social venture are formed. In: MAIR, J.; ROBINSON, J.; HOCKERTS, K.. Social Entrepreneurship. Palgrave Macmillan: Basingstoke, UK and New York, 2006.

MAMEDE, G.. O trabalho acadêmico: monografias, dissertações e teses. Belo Horizonte: Mandamentos, 2001.

MINAYO, M. C. S.. Pesquisa social: teoria, método e criatividade. 6 ed. Petrópolis: Vozes, 1996.

MORT, G. M. S; WEERAWARDENA, J.; CARNEGIE, K.. Social Entrepreneurship: Towards

Conceptualisation. International Journal of Nonprofit and Voluntary Sector Marketing, v.8, n.1, p.76-90. 2003.

MOZZATO, A. R.; GRZYBOVSKI, D.. Análise de Conteúdo como técnica de análise de dados qualitativos no campo da administração: potencial e desafios. Revista de Administração Contemporânea, v.15, n.4, p.731-747, 2011.

OLIVEIRA, E. M.. Empreendedorismo Social no Brasil: atual configuração, perspectivas e desafios - notas introdutórias. Revista FAE, Curitiba, v.7, n.2, p.9-18, 2004.

PEREDO, A. M.. Community venture in agua dulce: the evolution of civic into economic democracy. The Journal of Applied Behavioral Science, v.41, n.4, p.458-481. 2005. 
ROBINSON, J.. Navigating social and institutional barrierd to markets: How social entrepreneurs identify and evaluate opportunities. In: MAIR, J.; ROBINSON, J.; HOCKERT, K.. Social entrepreneurship. New York: Palgrave Macmillan. 2006.

SHANE, S.; VENKATARAMAN, S.. The promise of entrepreneurship as a field of research. Academy of Management Review, v.25, n.1, p.217-226. 2000.

SHAW, E.; CARTER, E.. Social entrepreneurship. Theoretical antecedents and empirical analysis of entrepreneurial processes and outcomes. Journal of Small Business and Enterprise Development, v.14 n.3, p.418-434. 2007.

SINGH, R. P.. A comment on developing the field of entrepreneurship through the study of opportunity recognition and exploitation. Academy of Management Review, v.26, n.1, p.10-12, 2001.

TEIXEIRA, M. C. S.; PORTO, M. R. S.. Violência, insegurança e imaginário do medo. Caderno CEDES, v.14, n.47, p.51-66, 1998.

TIMMONS, J. A.. New Venture Creation: Entrepreneurship for the 21. St. Century, Irwin.Boston, 1994.

VENTURA, M. M.. O Estudo de Caso como modalidade de pesquisa. Revista SOCERJ. Rio de Janeiro, Socerj, v.20, n.5, p.383-386, 2007.

WEERAWARDENA, J.; MORT, S. G.. Investigating social entrepreneurship: a multidimensional model. Journal of World Business, v.41, n.1, p.21-35. 2006.

YIN, R. K.. Estudo de Caso, planejamento e métodos. 2 ed. São Paulo: Bookman, 2001. 